\title{
Brain metastases in patients with EGFR -mutated or ALK -rearranged non-small-cell lung cancers
}

\section{Citation}

Rangachari, Deepa, Norihiro Yamaguchi, Paul A. VanderLaan, Erik Folch, Anand Mahadevan, Scott R. Floyd, Erik J. Uhlmann, et al. 2015. "Brain Metastases in Patients with EGFR -Mutated or ALK -Rearranged Non-Small-Cell Lung Cancers." Lung Cancer 88 (1) (April): 108-111. doi:10.1016/j.lungcan.2015.01.020.

\section{Published Version}

10.1016/j.lungcan.2015.01.020

\section{Permanent link}

http://nrs.harvard.edu/urn-3:HUL.InstRepos:37034617

\section{Terms of Use}

This article was downloaded from Harvard University's DASH repository, and is made available under the terms and conditions applicable to Open Access Policy Articles, as set forth at http:// nrs.harvard.edu/urn-3:HUL.InstRepos:dash.current.terms-of-use\#OAP

\section{Share Your Story}

The Harvard community has made this article openly available.

Please share how this access benefits you. Submit a story.

\section{Accessibility}


Published in final edited form as:

Lung Cancer. 2015 April ; 88(1): 108-111. doi:10.1016/j.lungcan.2015.01.020.

\section{Brain metastases in patients with EGFR-mutated or ALK- rearranged non-small-cell lung cancers}

Deepa Rangachari, MD ${ }^{1}$, Norihiro Yamaguchi, MD, MPH ${ }^{1}$, Paul A. VanderLaan, MD, PhD $^{2}$, Erik Folch, MD, MSc ${ }^{1,3}$, Anand Mahadevan, MD ${ }^{4}$, Scott R. Floyd, MD, PhD ${ }^{4}$, Erik J. Uhlmann, $\mathbf{M D}^{5}$, Eric T. Wong, $\mathrm{MD}^{5}$, Suzanne E. Dahlberg, $\mathrm{PhD}^{6}$, Mark S. Huberman, MD', and Daniel B. Costa, MD, PhD ${ }^{1, *}$

${ }^{1}$ Department of Medicine, Harvard Medical School, Boston, MA

${ }^{2}$ Department of Pathology, Harvard Medical School, Boston, MA

${ }^{3}$ Department of Surgery, Harvard Medical School, Boston, MA

${ }^{4}$ Department of Radiation Oncology, Harvard Medical School, Boston, MA

${ }^{5}$ Department of Neurology; Beth Israel Deaconess Medical Center, Harvard Medical School, Boston, MA

${ }^{6}$ Department of Biostatistics and Computational Biology, Dana-Farber Cancer Institute and Harvard School of Public Health, Harvard Medical School, Boston, MA

\section{Abstract}

Introduction-Brain metastases (BM) are common in non-small-cell lung cancer (NSCLC). However, the baseline incidence and evolution of BM over time in oncogene-driven NSCLCs are seldom reported. In this study, we evaluated the frequency of BM in patients with epidermal growth factor receptor $(E G F R)$-mutated or anaplastic lymphoma kinase $(A L K)$-rearranged NSCLC.

Methods-The presence of BM, clinicopathologic data, and tumor genotype were retrospectively compiled and analyzed from a cohort of 381 patients.

Results-We identified 86 EGFR-mutated (90.7\% with metastatic disease; $85.9 \%$ received an EGFR inhibitor) and $23 A L K$-rearranged (91.3\% with metastatic disease; $85.7 \%$ received an ALK inhibitor) NSCLCs. BM were present in $24.4 \%$ of $E G F R$-mutated and $23.8 \%$ of $A L K$-rearranged NSCLCs at the time of diagnosis of advanced disease. This study did not demonstrate a difference in the cumulative incidence of BM over time between the two cohorts (EGFR/ALK cohort

\footnotetext{
(C) 2015 Published by Elsevier Ltd.

This manuscript version is made available under the CC BY-NC-ND 4.0 license.

Corresponding Author: Daniel B. Costa, MD, PhD, Division of Hematology/Oncology, Beth Israel Deaconess Medical Center, 330 Brookline Ave., Boston, MA 02215, Phone: 617-667-9236, Fax: 617-975-5665, dbcosta@bidmc.harvard.edu.

Publisher's Disclaimer: This is a PDF file of an unedited manuscript that has been accepted for publication. As a service to our customers we are providing this early version of the manuscript. The manuscript will undergo copyediting, typesetting, and review of the resulting proof before it is published in its final citable form. Please note that during the production process errors may be discovered which could affect the content, and all legal disclaimers that apply to the journal pertain.

Conflict of interest: annexed separately.
} 
competing risk regression [CRR] coefficient of 0.78 [95\% CI 0.44-1.39], $\mathrm{p}=0.41$ ). In still living patients with advanced EGFR-mutated NSCLC, $34.2 \%$ had BM at 1 year, $38.4 \%$ at 2 years, $46.7 \%$ at 3 years, $48.7 \%$ at 4 years, and $52.9 \%$ at 5 years. In still living patients with advanced $A L K$ rearranged NSCLC, $23.8 \%$ had BM at 1 year, $45.5 \%$ at 2 years, and $58.4 \%$ at 3 years.

Conclusions-BM are frequent in advanced $E G F R$-mutated or $A L K$-rearranged NSCLCs, with an estimated $>45 \%$ of patients with CNS involvement by three years of survival with the use of targeted therapies. These data point toward the CNS as an important unmet clinical need in the evolving schema for personalized care in NSCLC.

\section{Keywords}

lung cancer; NSCLC; brain metastases; EGFR; ALK; mutation; rearrangement; central nervous system; CNS

\section{INTRODUCTION}

Non-small-cell lung cancer (NSCLC) is the leading cause of brain metastases (BM) (1). Amongst those with recurrent/advanced NSCLC, BM are a common culprit for cancerrelated morbidity and mortality. The incidence of BM in NSCLC has been reported as $>20 \%$ at diagnosis, with a significant proportion of patients developing BM over the course of their disease $(2,3)$. Recent reports also demonstrate an increase in the documented incidence of BM in NSCLC, likely as a consequence of prolonged survival with newer therapies coupled with improvements in neuroimaging modalities (4).

Far less is known about the baseline incidence and subsequent evolution of BM in the subset of patients with oncogene-driven tumors, i.e. epidermal growth factor $(E G F R)$-mutated or anaplastic lymphoma kinase $(A L K)$-rearranged $\operatorname{NSCLC}(5,6)$. Given the growing emphasis on molecular profiling and use of targeted therapeutics (7), this is a critical population. An improved understanding of the incidence and evolution of BM in these cases is therefore an area of ongoing need.

Herein, we report the baseline and cumulative incidence of BM in patients with EGFRmutated or $A L K$-rearranged advanced NSCLC.

\section{MATERIALS AND METHODS}

\section{Cohort selection}

Patients seen at Beth Israel Deaconess Medical Center (BIDMC) with a diagnosis of NSCLC and whose tumors were genotyped were identified through an ongoing Institutional Review Board-approved study (8,9), with a data cutoff of December 19, 2012 for patient inclusion and June 24, 2014 for outcomes.

\section{Tumor genotype}

EGFR mutation analysis (exons 18 to 21 ) was performed using standard sequencing techniques, and $A L K$ rearrangement was analyzed using the Vysis $A L K$ break-apart fluorescence in situ hybridization (FISH) probe (8). 


\section{Data collection and detection of BM}

Data was collected by retrospective chart review and managed using REDCap electronic data capture tools hosted at BIDMC. All patients with advanced NSCLC (stage IV/recurrent disease) had baseline CNS evaluation with either computed tomography (CT) or magnetic resonance imaging (MRI). Subsequent CNS assessment was performed at the discretion of the treating physicians. BM were diagnosed either radiographically or pathologically (tumor resection/biopsy or malignant CSF cytology).

\section{Statistical methods}

Fisher's exact test was used to compare categorical variables, and Wilcoxon rank test was used for continuous variables. All p-values reported are two-sided, and tests were conducted at the 0.05-level. Time to BM was defined as the time from diagnosis to date of detected $\mathrm{BM}$, and cumulative incidence curves were fitted and compared using the methodologies of Fine and Gray (10), adjusting for death as a competing risk. Patients not experiencing BM or death by the time of data cutoff were censored at their last date of follow-up. Overall survival (OS) was analyzed using the Kaplan-Meier method. Statistical analyses and curves were performed with the cmprsk package in R Statistical Programming Language.

\section{RESULTS}

\section{Patient and tumor characteristics}

The complete cohort comprised 381 patients, with a median age at diagnosis of 65 years. Self-reported racial groups were $75.9 \%$ white, $13.1 \%$ Asian, $6.5 \%$ black, and $4.4 \%$ other. $27.8 \%$ of patients were never smokers, $54.9 \%$ were former smokers, and $17.3 \%$ current smokers. At the time of initial entry into the cohort, $73.8 \%$ had stage IV/recurrent disease, and $86.1 \%$ had adenocarcinoma histology. EGFR and $A L K$ analysis was successful in $94.2 \%$ (359/381) and $91.6 \%$ (252/275) of tested samples, respectively (8). The overall frequency of EGFR mutations and ALK FISH positivity was $23.9 \%$ (86/359) and 9.1\% (23/252), respectively. Abnormalities in $E G F R$ and $A L K$ were mutually exclusive in all genotyped tumors.

\section{Characteristics of EGFR-mutated or ALK-rearranged NSCLCs}

The EGFR-mutated cohort was comprised of more women; however, both cohorts predominantly involved patients with no tobacco history, advanced disease, and adenocarcinoma histology (Table 1). 85.9\% (67/86) of patients with EGFR-mutated NSCLCs received an EGFR tyrosine kinase inhibitor (TKI) -gefitinib, erlotinib, or dacomitinib - at some point in their treatment course. 85.7\% (18/23) of patients with $A L K$ rearranged NSCLCs received the $A L K$ TKI, crizotinib (Table 1). The median follow-up for patients with $E G F R$-mutated and $A L K$-rearranged NSCLC was 45.2 and 36.4 months, respectively. 


\section{BM in EGFR-mutated NSCLC}

$24.4 \%$ (19/78) of the patients with EGFR-mutated NSCLC had BM at initial evaluation. The cumulative incidence of post-diagnosis BM increased over time (Figure 1A): $34.2 \%$ at 1 year, $38.4 \%$ at 2 years, $46.7 \%$ at 3 years, $48.7 \%$ at 4 years, and $52.9 \%$ at 5 years.

\section{BM in ALK-rearranged NSCLC}

$23.8 \%(5 / 21)$ of the patients with $A L K$-rearranged NSCLC had BM at initial evaluation. The cumulative incidence of post-diagnosis BM increased over time (Figure 1A): $23.8 \%$ at 1 year, $45.5 \%$ at 2 years, and $58.4 \%$ at 3 years. At the time of data cutoff, none of the patients with $A L K$-rearranged NSCLC had reached beyond the 4-year survival mark.

\section{Differences in BM between EGFR-mutated and ALK-rearranged NSCLC}

No statistically significant difference was observed in the baseline and subsequent incidence of BM with $E G F R$-mutated versus $A L K$-rearranged tumors (Figure 1A). Additionally, this study did not demonstrate a difference in the cumulative incidence of BM over time between the two cohorts ( $E G F R / A L K$ cohort CRR coefficient of 0.78 [95\% CI 0.44-1.39], p=0.41). However, since the $A L K$-rearranged cohort had fewer patients and less follow-up time than the $E G F R$-mutated group, it is unknown if differences may have evolved during subsequent follow-up.

\section{Overall survival}

Survival curves are depicted in Figure 1B. Amongst the 78 patients with an EGFR mutation, the median OS was 34.4 months (95\% CI 28.1-49.1). Median OS amongst the 21 patients with an $A L K$ rearrangement was 38.3 months (95\% CI 22.3-NA).

\section{DISCUSSION}

We retrospectively evaluated a cohort of patients with $E G F R$-mutated or $A L K$-rearranged advanced NSCLC. BM were common, with nearly $25 \%$ of patients with BM at initial diagnosis and approximately half of patients with BM by 3 years in the setting of precision therapies. Limitations of this study include its retrospective nature and the lack of a standardized protocol for CNS assessment. Nevertheless, to our knowledge, this is the largest study to assess the baseline incidence and subsequent evolution of BM in these molecularly-defined groups.

The clinical course of patients with these oncogene-driven NSCLCs is an area of ongoing investigation. The University of Colorado evaluated patterns of metastatic spread in 209 patients with treatment-naïve $E G F R$-mutated, $K R A S$-mutated, $A L K$-rearranged, and $E G F R /$ $K R A S / A L K$-unaffected advanced NSCLC (11). Similar to our findings, BM was present at diagnosis in $23 \%$ and $24 \%$ of $E G F R$-mutated and $A L K$-rearranged patients, respectively (11). In one retrospective study, BM were reported in 8\% (5 of 62) EGFR-mutated patients at diagnosis, with an additional $24 \%$ diagnosed with BM at follow-up (12). The overall incidence of BM in this cohort was $32 \%$, and time to BM and post-BM survival were 20.8 and 12.1 months, respectively (12). One other study of 93 patients with NSCLC and BM undergoing mutational analysis for EGFR found 49\% (20 of 41) of EGFR-mutated NSCLCs 
with synchronous $\mathrm{BM}$ at the time of initial diagnosis (13). Time to progression in the brain was non-significantly longer in EGFR-mutated NSCLCs as compared to those with wildtype EGFR (13). The prevalence of BM in the published trials of TKIs in advanced NSCLC to-date is similarly impressive, with more than $10 \%$ of patients in the first line trials of EGFR TKIs (5) and 35\% of patients in the second line trials of ALK TKIs (6) noted to have baseline asymptomatic BM.

As targeted therapies continue to improve outcomes for patients with molecularly-driven NSCLCs (5-7), the deterrence of BM has become an increasingly relevant therapeutic dilemma. Most available TKIs (gefitinib, erlotinib, and crizotinib) inefficiently cross the intact blood-brain barrier with cerebrospinal fluid-to-plasma ratios as low as 0.01 to 0.003 detected in patients (14). Even so, it seems that their use can still alter the natural history of BM. In one report of 155 EGFR-mutated NSCLCs, the 12- and 24-month cumulative risk of CNS progression was $6 \%$ and $21 \%$ in the group initially treated with an EGFR TKI, as compared to $19 \%$ and $32 \%$ in the group receiving first line chemotherapy; a hazard ratio of 0.56 (95\% CI 0.34-0.94) was noted for CNS progression, favoring upfront EGFR TKI over chemotherapy (15). Although a similar comparison has not been performed for $A L K$ rearranged NSCLC, crizotinib and other $A L K$ TKIs (such as ceritinib and alectinib) can also positively influence CNS disease (7). Ceritinib and alectinib have reported CNS activity in patients with ALK-rearranged NSCLC that are naïve or resistant to crizotinib therapy (7). Since our group's cohort and those of others (5-7) predominantly studied patients that received TKIs, it is tempting to postulate that the cumulative incidence of BM may have been even higher in patients treated with chemotherapy alone. Contemporary clinical trials of novel EGFR and ALK TKIs now mandate baseline CNS imaging at study entry for all patients and have started to stratify patients based on presence/absence of BM. Such efforts will hopefully define prospectively whether CNS and systemic sites differ in patterns of response/progression in the setting of TKI use (7). Moreover, these studies will aid in delineating strategies for optimal surveillance for and detection of BM early in the course of CNS progression, for which there is currently no established standard.

Acquired resistance to targeted therapies remains a key limitation in achieving a durable benefit. Even as the major mechanisms of acquired systemic resistance are known to result from resistant tyrosine kinase mutations and activation of bypass pathways (7), the mechanisms that explain CNS progression remain largely unknown. As reported here and elsewhere $(5-7,10-12)$, the CNS is amongst the most frequent sites of disease progression in patients whose systemic disease is otherwise being successfully controlled with TKIs. The optimal management of BM in oncogene-driven NSCLCs remains uncertain, and the use of whole brain or stereotactic radiotherapy remains a cornerstone of care (16).

In conclusion, this retrospective study demonstrates the high initial incidence (nearly 25\%) and subsequent prevalence of $\mathrm{BM}$ in patients with advanced EGFR-mutated or $A L K$ rearranged NSCLCs treated with TKIs. Given their frequency in tumors with these driver mutations, increased inclusion of patients with BM in innovative trials of targeted therapies will be critical in defining their full potential and facilitating their application in real-world practice. Developing optimal strategies for the prevention and management of CNS disease has become one of the foremost clinical questions in the care of these patients. Future 
studies should address the role of TKIs with improved CNS penetration, the use of less toxic radiotherapy techniques for $\mathrm{BM}$, and the need to better understand the molecular underpinnings of malignant CNS disease.

\section{Acknowledgments}

This work was funded in part through a fellowship from the American Society of Clinical Oncology Conquer Cancer Foundation (DBC), an American Cancer Society grant (RSG 11-186 to DBC), a Lung Cancer Foundation of America-International Association for the Study of Lung Cancer grant (to DBC), National Institutes of Health (NIH) grant CA090578 (to DBC), and Gallup Funds from the Thoracic Oncology Program at the Dana-Farber Cancer Institute (to SED).

\section{References}

1. Nayak L, Lee EQ, Wen PY. Epidemiology of brain metastases. Curr Oncol Rep. 2012; 14:48-54. [PubMed: 22012633]

2. Shi AA, Digumarthy SR, Temel JS, Halpern EF, Kuester LB, Aquino SL. Does initial staging or tumor histology better identify asymptomatic brain metastases in patients with non-small cell lung cancer? J Thorac Oncol. 2006; 1:205-10. [PubMed: 17409858]

3. Heon S, Yeap BY, Britt GJ, Costa DB, Rabin MS, Jackman DM, et al. Development of central nervous system metastases in patients with advanced non-small cell lung cancer and somatic EGFR mutations treated with gefitinib or erlotinib. Clin Cancer Res. 2010; 16:5873-82. [PubMed: 21030498]

4. Barnholtz-Sloan JS, Sloan AE, Davis FG, Vigneau FD, Lai P, Sawaya RE. Incidence proportions of brain metastases in patients diagnosed (1973 to 2001) in the Metropolitan Detroit Cancer Surveillance System. J Clin Oncol. 2004; 22:2865-72. [PubMed: 15254054]

5. Rosell R, Carcereny E, Gervais R, Vergnenegre A, Massuti B, Felip E, et al. Erlotinib versus standard chemotherapy as first-line treatment for European patients with advanced EGFR mutationpositive non-small-cell lung cancer (EURTAC): a multicentre, open-label, randomised phase 3 trial. Lancet Oncol. 2012; 13:239-46. [PubMed: 22285168]

6. Shaw AT, Kim DW, Nakagawa K, Seto T, Crino L, Ahn MJ, et al. Crizotinib versus chemotherapy in advanced ALK-positive lung cancer. N Engl J Med. 2013; 368:2385-94. [PubMed: 23724913]

7. Gerber DE, Gandhi L, Costa DB. Management and future directions in non-small cell lung cancer with known activating mutations. Am Soc Clin Oncol Educ Book. 2014:e353-e365. [PubMed: 24857124]

8. VanderLaan PA, Yamaguchi N, Folch E, Boucher DH, Kent MS, Gangadharan SP, et al. Success and failure rates of tumor genotyping techniques in routine pathological samples with non-smallcell lung cancer. Lung Cancer. 2014; 84:39-44. [PubMed: 24513263]

9. Yamaguchi N, VanderLaan PA, Folch E, Boucher DH, Canepa HM, Kent MS, et al. Smoking status and self-reported race affect the frequency of clinically relevant oncogenic alterations in non-smallcell lung cancers at a United States-based academic medical practice. Lung Cancer. 2013; 82:31-7. [PubMed: 23932486]

10. Fine JP, Grayzel D. A Proportional Hazards Model for the Subdistribution of a Competing Risk. Journal of the American Statistical Association. 1999; 94:496-509.

11. Doebele RC, Lu X, Sumey C, Maxson DA, Weickhardt AJ, Oton AB, et al. Oncogene status predicts patterns of metastatic spread in treatment-naive nonsmall cell lung cancer. Cancer. 2012; 118:4502-11. [PubMed: 22282022]

12. Hendriks LE, Smit EF, Vosse BA, Mellema WW, Heideman DA, Bootsma GP, et al. EGFR mutated non-small cell lung cancer patients: more prone to development of bone and brain metastases? Lung Cancer. 2014; 84:86-91. [PubMed: 24529684]

13. Eichler AF, Kahle KT, Wang DL, Joshi VA, Willers H, Engelman JA, et al. EGFR mutation status and survival after diagnosis of brain metastasis in nonsmall cell lung cancer. Neuro Oncol. 2010; 12:1193-9. [PubMed: 20627894] 
14. Costa DB, Kobayashi S, Pandya SS, Yeo WL, Shen Z, Tan W, et al. CSF concentration of the anaplastic lymphoma kinase inhibitor crizotinib. J Clin Oncol. 2011; 29:e443-e445. [PubMed: 21422405]

15. Heon S, Yeap BY, Lindeman NI, Joshi VA, Butaney M, Britt GJ, et al. The impact of initial gefitinib or erlotinib versus chemotherapy on central nervous system progression in advanced nonsmall cell lung cancer with EGFR mutations. Clin Cancer Res. 2012; 18:4406-14. [PubMed: 22733536]

16. Zimmermann S, Dziadziuszko R, Peters S. Indications and limitations of chemotherapy and targeted agents in non-small cell lung cancer brain metastases. Cancer Treat Rev. 2014; 40:71622. [PubMed: 24759599] 


\section{HIGHLIGHTS}

- $\quad$ Brain metastases are frequent in $A L K$ rearranged lung cancers

- $\quad$ Brain metastases are frequent in EGFR mutated lung cancers

- $\quad \sim 25 \%$ of patients at diagnosis and half at 3-years of survival have brain metastases 

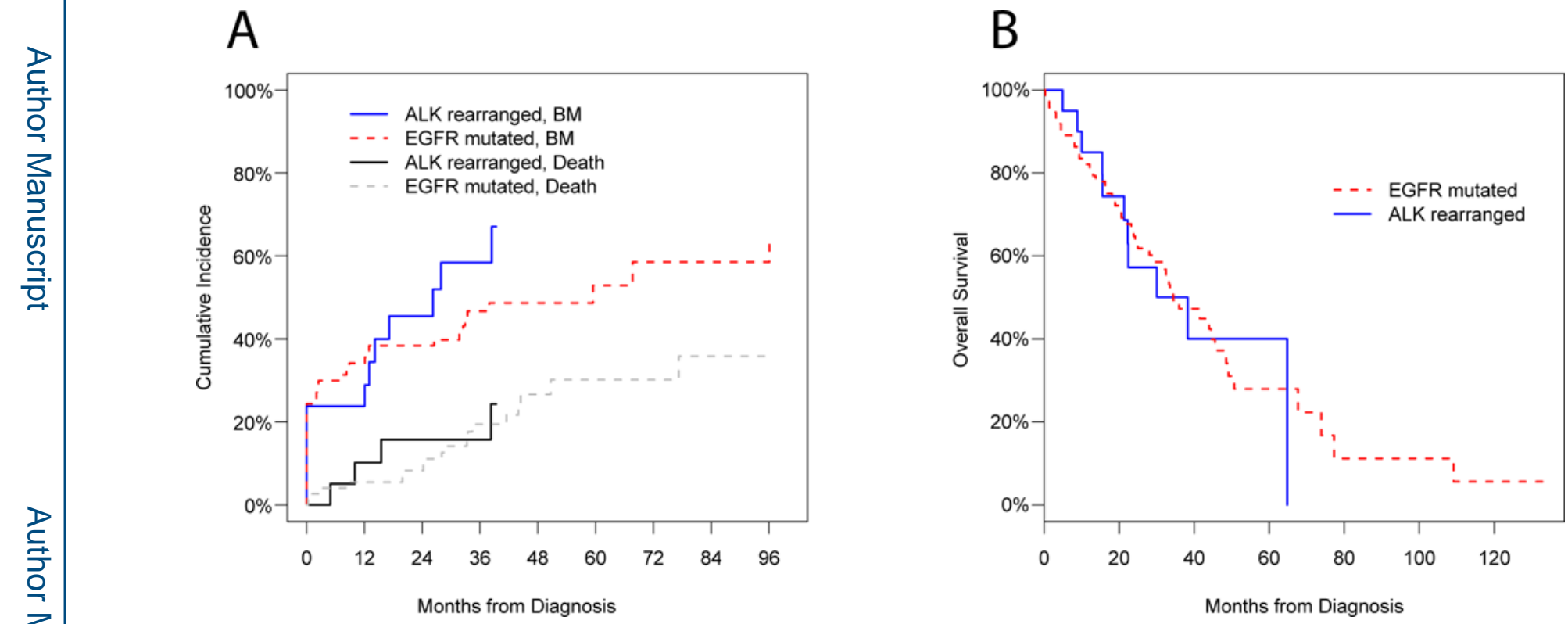

Figure 1. 
Table 1

Baseline characteristics of patients and tumors with EGFR-mutated and $A L K$-rearranged NSCLC.

\begin{tabular}{|c|c|c|c|}
\hline & \multicolumn{3}{|c|}{ Tumor genotype } \\
\hline & $\begin{array}{c}E G F R \text {-mutated } \\
(\mathrm{n}=86)\end{array}$ & $\underset{(\mathrm{n}=23)}{A L K \text {-rearranged }}$ & $p$-value \\
\hline \multicolumn{4}{|l|}{ Age at time of biopsy } \\
\hline Median (range) & $65(33-90)$ & $56(29-80)$ & $<0.0001^{*}$ \\
\hline Women n (\%) & $64(74.4)$ & $11(47.8)$ & 0.0218 \\
\hline \multicolumn{4}{|l|}{ Race n $(\%)$} \\
\hline White & $50(58.1)$ & $15(65.2)$ & 0.6357 \\
\hline Asian & $31(36.1)$ & $4(17.4)$ & \\
\hline Black & $4(4.6)$ & $0(0)$ & \\
\hline Other & $1(1.2)$ & $4(17.4)$ & \\
\hline \multicolumn{4}{|l|}{ Smoking status n (\%) } \\
\hline Current smoker & $4(4.65)$ & $1(4.3)$ & 0.4909 \\
\hline Former smoker & $37(43.0)$ & $8(34.8)$ & \\
\hline Never smoker & $45(52.3)$ & $14(60.9)$ & \\
\hline \multicolumn{4}{|l|}{ Stage n $(\%)$} \\
\hline I-III & $8(9.3)$ & $2(8.7)$ & 1.0000 \\
\hline IV/recurrent & $78(90.7)$ & $21(91.3)$ & \\
\hline \multicolumn{4}{|l|}{ Histology n (\%) } \\
\hline Adenocarcinoma & $84(97.7)$ & $21(91.3)$ & 0.1952 \\
\hline Squamous cell carcinoma & $0(0)$ & $1(4.3)$ & \\
\hline NSCLC (NOS) & $2(2.3)$ & $1(4.3)$ & \\
\hline \multicolumn{4}{|l|}{ Use of precision TKI n (\%) } \\
\hline When stage IV/recurrent & $67(85.9)$ & $18(85.7)$ & 1.0000 \\
\hline \multicolumn{4}{|l|}{ Baseline brain metastases n (\%) } \\
\hline When stage IV/recurrent & $19(24.4)$ & $5(23.8)$ & 1.0000 \\
\hline
\end{tabular}

NSCLC $=$ non-small-cell lung cancer; NOS $=$ not otherwise specified; TKI = tyrosine kinase inhibitor.

*Wilcoxon-Rank Sum test 